\title{
The Tactile-Stimulated Startle Response of Tadpoles: Acceleration Performance and its Relationship to the Anatomy of Wood Frog (Rana sylvatica), Bullfrog (Rana catesbeiana), and American Toad (Bufo americanus) Tadpoles
}

\author{
LAURA EIDIETIS* \\ Department of Ecology and Evolutionary Biology, University of Michigan, \\ Ann Arbor, Michigan 48109-1048
}

\begin{abstract}
I described the tactile-stimulated startle response (TSR) of wood frog (Rana sylvatica), bullfrog (Rana catesbeiana), and American toad (Bufo americanus) tadpoles. One purpose was to rank species in terms of maximum acceleration performance. Also, I tested whether anatomical indicators of performance potential were predictive of realized performance. TSRs were elicited in a laboratory setting, filmed at $250 \mathrm{~Hz}$, and digitally analyzed. TSRs began with two, initial body curls during which tadpoles showed a broad spectrum of movement patterns. TSR performance was quantified by maximum linear acceleration and maximum rotational acceleration of the head/ body, both of which tended to occur immediately upon initiation of motion $(<0.012$ sec into the response). Bullfrog tadpoles had higher maximum acceleration than the other species, but other interspecific differences were not significant. The species' rank order for the anatomical indicator of linear acceleration potential was bullfrog $>$ wood frog $>$ American toad. The species' rank order for the anatomical indicator of rotational acceleration potential was bullfrog $>$ wood frog $=$ American toad. Thus, the anatomical indicators roughly predicted the rank order of interspecific average performance. However, the anatomical indicators did not correlate with individual tadpole performance. Variability in behavioral patterns may obscure the connection between anatomy and performance. This is seen in the current lack of intraspecific correlation between a morphological indicator of acceleration capacity and acceleration performance. J. Exp. Zool. 305A:348-362, 2006.

(C) 2006 Wiley-Liss, Inc.
\end{abstract}

The anuran tadpole initiates its escape from a predator with a tactile-stimulated startle response (TSR, see Table 1 for list of acronyms and variables) (Van Buskirk and McCollum, 2000; Johnson and Eidietis, 2005; Teplitsky et al., 2005). TSRs are initiated upon contact (Pritchard, '65; Van Buskirk and McCollum, 2000; Zottoli et al., 2001; Teplitsky et al., 2005; Johnson and Eidietis, in press) and, thus, apparently have the purpose of breaking contact with the mouthparts of predators (as opposed to evading or avoiding a predator). The tadpole can utilize large-amplitude body motions to generate momentum allowing it to tear from the grasp of a predator (Morin, '85; Doherty et al., '98; Blair and Wassersug, 2000; Johnson and Eidietis, in press). In this case, escape success depends upon the muscle force available and the fragility of the tissue that is in the grasp of the predator (Doherty et al., '98).
Alternatively, the tadpole can quickly accelerate the point of contact before the predator is able to grasp or pierce the tadpole (Johnson and Eidietis, 2005). In this situation, a tadpole TSR serves to quickly jerk a point on the body away from contact with a predator, where "jerk" refers to a brief, quick change in momentum. For tadpoles that are free to move (i.e., motion is not limited by the grasp of a predator), the kinematic result of a jerk is a peak in acceleration. These peaks are brief being sustained for $<0.008 \mathrm{~s}$ in wood frog (Rana sylvatica) TSRs (Eidietis, 2005). Because

Grant sponsor: National Science Foundation Grant; Grant number: IBN 9973942.

*Correspondence to: L. Eidietis, Eastern Michigan University, Biology Department, Ypsilanti, MI 48197. E-mail: leidieti@emich.edu Received 8 August 2005; Accepted 2 December 2005

Published online in Wiley InterScience (www.interscience.wiley. com). DOI: 10.1002/jez.a.269. 
TABLE 1. List of acronyms and symbols used in the text

\begin{tabular}{|c|c|c|}
\hline \multirow[t]{8}{*}{ Acronyms } & BTI & Head/body-tail intersection \\
\hline & COR & Point on the head/body that moves least; center of resistance \\
\hline & CSA & Physiological muscle cross sectional area \\
\hline & $\mathrm{HL}$ & Head/body length \\
\hline & NPE & Not predator-exposed \\
\hline & $\mathrm{PE}$ & Predator-exposed \\
\hline & $\mathrm{TL}$ & Tail length \\
\hline & TSR & Tactile-stimulated startle response \\
\hline \multirow[t]{25}{*}{ Symbols } & $a$ & Linear acceleration of the COR \\
\hline & $a_{\max }$ & Maximum linear acceleration of the COR \\
\hline & $\alpha$ & Rotational acceleration of the head/body \\
\hline & $\alpha_{\max }$ & Maximum rotational acceleration of the head/body \\
\hline & $\mathrm{CSA}_{\text {mus }}$ & Muscle cross sectional area at the BTI \\
\hline & $d_{\text {slab }}$ & Depth of a dorso-ventrally flattened slab used to estimate $I_{\mathrm{H} / \mathrm{B}}$ \\
\hline & $F_{\text {msucle }}$ & Maximum capability of the tail muscle to produce force \\
\hline & $\gamma$ & Rotational added mass coefficient \\
\hline & $I_{\mathrm{H} / \mathrm{B}}$ & Moment of inertia of the head/body relative to the COR \\
\hline & $l_{\text {slab }}$ & Major axis of an elliptical, dorso-ventrally flattened slab used to estimate $I_{\mathrm{H} / \mathrm{B}}$ \\
\hline & $L$ & Moment arm \\
\hline & $\eta$ & Added mass coefficient \\
\hline & $m_{\mathrm{H} / \mathrm{B}}$ & Mass of the head/body \\
\hline & $m_{\text {slab }}$ & Mass of an elliptical, dorso-ventrally flattened slab used to estimate $I_{\mathrm{H} / \mathrm{B}}$ \\
\hline & $M$ & Tadpole mass \\
\hline & $\rho$ & Density of water \\
\hline & $R_{\mathrm{a}}$ & Resistance to linear acceleration of the head/body \\
\hline & $R_{\alpha}$ & Resistance to rotational acceleration of the head/body \\
\hline & $S$ & Number of dorso-ventrally flattened slabs used to model the head/body \\
\hline & $\tau_{\text {muscle }}$ & Maximum capability of the tail muscle to produce torque to rotate the head/body \\
\hline & $v_{\text {slab }}$ & Volume of an elliptical, dorso-ventrally flattened slab used to estimate $I_{\mathrm{H} / \mathrm{B}}$ \\
\hline & $V$ & Volume of the head/body \\
\hline & $w_{\text {slab }}$ & Minor axis of an elliptical dorso-ventrally flattened slab used to estimate $I_{\mathrm{H} / \mathrm{B}}$ \\
\hline & $X$ & Distance from the BTI to the COR \\
\hline & $x_{\text {slab }}$ & Distance from the center of mass of a dorso-ventrally flattened slab to the COR \\
\hline
\end{tabular}

strikes aimed between the nose and head/ body-tail intersection (BTI) (Fig. 1) are reported to be more common and more deadly than strikes at the tail (Van Buskirk et al., 2003, 2004; Johnson and Eidietis, in press), the ability to jerk the head/ body is likely to be pertinent to tadpole survival. Therefore, one behaviorally relevant measure of performance is the maximal level of head/body acceleration obtained during acceleration jerks.

Both linear and rotational acceleration of the head/body can cause points on the head/body to jerk. As noted above, researchers report that the first two stages of the tadpole TSR include short, time-dependent peaks in linear acceleration of the head/body (Hoff, '88; Wilson and Franklin, '99, 2000; Eidietis, 2005). Similar time dependence of rotational acceleration has not yet been described. However, given the changes in rotational direction of the head/body during stages I and II of the TSR (Van Buskirk and McCollum, 2000; Eidietis, 2005), peaks in rotational acceleration are likely.

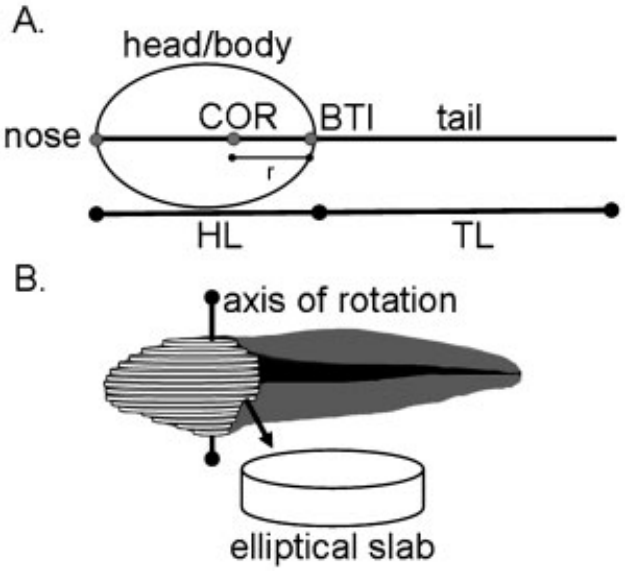

Fig. 1. (A) A ventral view of a tadpole notated with morphological references: the center of resistance (COR) of the head/body, the head/body-tail intersection (BTI), head length (HL) and tail length (TL). (B) The head/body was modeled as a stack of 15 flattened, elliptical slabs, and the moment of inertia was calculated relative to an axis at the COR. 
Assuming such rotational acceleration peaks occur, TSR performance should be measured both by maximum rotational acceleration performance and maximum linear acceleration performance.

The TSR occurs when a tadpole has no spatial or temporal separation from the mortal threat posed by a predator. Therefore, the behavioral choices of a tadpole during the TSR are limited, and it is expected that tadpoles perform maximally (Webb, '86). Maximal performance may not be equivalent among species with anatomical differences. Accordingly, the purpose of this investigation was, first, to determine if anatomically different tadpole species show interspecific variation in TSR performance.

Once differential performance is established, it is useful to examine its anatomical cause. Determining proximal mechanisms controlling performance aids in the understanding of ecomorphological trends (e.g., Webb, '88; Webb and Gerstner, 2000; Wainwright et al., 2002) and informs adaptive hypotheses regarding local optima and tradeoffs (Seger and Stubblefield, '96). For this reason, I identified anatomical indicators of maximal acceleration performance and described variation in these metrics. I accomplished this using a simple, conceptual model of acceleration performance as a result of the balance between force and torque production and inertial resistance. Finally, I considered whether the anatomical indicators of performance capacity were predictive of realized performance.

The species compared were the wood frog, the bullfrog (Rana catesbeiana), and the American toad (Bufo americanus). These were chosen primarily because they are known to vary in morphology (Richardson, 2002; Larson, 2005), suggesting, a priori, they may also show variation in the anatomical indicators of acceleration ability.

\section{MATERIALS AND METHODS}

\section{Anatomical indicators of maximum acceleration potential}

Acceleration performance results from the balance between the production of force and torque and the resistance to linear and rotational acceleration. Acceleration of the head/body has a linear component which affects the velocity as measured at the point on the head/body that moves least (center of resistance, COR) (Fig. 1), and a rotational component, which causes the angular acceleration of the head/body around the COR. The force causing acceleration is limited by the maximum capability of the tail muscle to produce force $\left(F_{\text {muscle }}\right)$, and

$$
F_{\text {muscle }} \propto \mathrm{CSA},
$$

where CSA is the physiological cross-sectional area of the muscle. The muscle force acts at a distance from the COR. Therefore, the maximum capability of the tail muscle to produce torque to rotate the head/body ( $\left.T_{\text {muscle }}\right)$ will depend upon a moment $\operatorname{arm}(L)$ such that

$$
T_{\text {muscle }} \propto \mathrm{L} \cdot \mathrm{CSA} .
$$

I assumed that, during the TSR, the tadpole head/ body moves in a hydrodynamic regime in which inertial forces resist acceleration, but viscous forces are negligible (unpublished preliminary analysis). In this high Reynolds number regime, drag resistance is negligible in comparison with acceleration reaction (Daniel, '84).

Acceleration reaction resistance, the resistance to linear acceleration of the head/body $\left(R_{\mathrm{a}}\right)$ is given by

$$
R_{\mathrm{a}}=\eta \rho V+m_{\mathrm{H} / \mathrm{B}},
$$

where $\eta$ is the added mass coefficient (Daniel, '84; Denny, '93); $\rho$ is the density of water; and $V$ is the volume of the head/body. The first term in Eq. (3) is an estimate of the added mass force and $m_{\mathrm{H} / \mathrm{B}}$ is the inertial resistance (mass) of the head/body. For rotational acceleration of the head/body, the resistance $\left(R_{\alpha}\right)$ is

$$
R_{\alpha}=\gamma \rho V+I_{\mathrm{H} / \mathrm{B}},
$$

where $\gamma$ is the rotational added mass coefficient (Brennen, '82; c.f. Daniel and Meyhofer, '89) and $I_{\mathrm{H} / \mathrm{B}}$ is the rotational moment of inertia. I assumed that the axis of rotation for $I_{\mathrm{H} / \mathrm{B}}$ was at the COR.

To predict performance from anatomy, clear anatomical indicators of the variables described above are required. CSA can be estimated by the gross, anatomical maximum cross-sectional area of the muscle that is contracted to produce force (e.g., Carroll et al., 2004). For the tadpoles used in this analysis, the maximum cross-sectional area of the tail muscle occurs approximately at the BTI (preliminary observation). Therefore, I estimated physiological cross-sectional area as the muscle CSA at the BTI, $\mathrm{CSA}_{\text {mus. }}$ I estimated $L$ as the distance between the BTI and the COR, $X$; therefore, the maximum value for $T_{\text {muscle }}$ was estimated by $\mathrm{CSA}_{\text {mus }} X$.

To determine anatomical indicators of resistance, I assumed that the density of the tadpole head/ body is $\sim 1 \mathrm{~g} / \mathrm{cm}^{3}$ at $19^{\circ} \mathrm{C}$ (Gee and Waldick, '95). 
Thus, $\rho V \sim m_{\mathrm{H} / \mathrm{B}}$ and, for resistance to linear acceleration of the head/body, Eq. (3) reduces to

$$
R_{\mathrm{a}} \sim(\eta+1) m_{\mathrm{H} / \mathrm{B}}
$$

$R_{\mathrm{a}}$ is proportional to $m_{\mathrm{H} / \mathrm{B}}$, with $\eta$ determining the proportionality constant. Similarly, for resistance to rotational acceleration, Eq. (4) reduces to

$$
R_{\alpha} \sim \gamma m_{\mathrm{H} / \mathrm{B}}+I_{\mathrm{H} / \mathrm{B}} .
$$

$R_{\alpha}$ is dependent on $I_{\mathrm{H} / \mathrm{B}}$ and $m_{\mathrm{H} / \mathrm{B}}$, but the level of dependence upon $m_{\mathrm{H} / \mathrm{B}}$ is determined by $\gamma$.

Determination of $\eta$ and $\gamma$ for biological shapes is logistically challenging. One approach is to empirically measure these coefficients (Webb, '77; Daniel, '85; Daniel and Meyhofer, '89), but this was beyond the scope of the current study. A second approach is to estimate $\eta$ and $\gamma$ to be those of a more regularly shaped object for which these coefficients are known (Brennen, '82; Daniel and Meyhofer, '89; Johansson, 2003). However, the tadpole head/body does not closely resemble any regularly shaped object. Therefore, making such an estimate would introduce a source of error.

Alternatively, I considered that $\eta$ is dependent upon shape and, because tadpole head/bodies do not vary substantially among these species, $\eta$ is likely to be constant among species. A sensitivity analysis showed that values of $\eta$ between 0 and 1 did not change the interspecific rankings of resistance. Therefore, I elected to estimate $R_{\mathrm{a}}$ by $m_{\mathrm{H} / \mathrm{B}}$ and accept the unknown $\eta$ as a known source of error in the data. Similarly, $\gamma$ is dependent upon shape and likely to be reasonably constant among these species. A sensitivity analysis showed that values of $\gamma$ between 0 and 1 did not change the interspecific rankings of resistance to rotational acceleration of the head/body. Moreover, if the tadpole head is estimated to be a prolate ellipsoid (Daniel and Meyhofer, '89; Johansson, 2003), $\gamma$ is on the order of $10^{-2}$, making $\gamma \cdot m_{\mathrm{H} / \mathrm{B}}$ less than or equal to $10 \%$ of $I_{\mathrm{H} / \mathrm{B}}$ for all but two outlier American toad tadpoles (for which $\gamma \cdot m_{\mathrm{H} / \mathrm{B}}$ was $18 \%$ and $21 \%$ of $\left.I_{\mathrm{H} / \mathrm{B}}\right)$. Therefore, I elected to estimate $R_{\alpha}$ as $I_{\mathrm{H} / \mathrm{B}}$, accepting $\gamma \cdot m_{\mathrm{H} / \mathrm{B}}$ as a source of error that is not expected to strongly affect interspecific rankings of resistance.

I estimated $I_{\mathrm{H} / \mathrm{B}}$ by geometrically modeling the head/body as a stack of horizontal slices rotating about a vertical axis at the COR (Fig. 1B). The slices were assumed to be elliptical slabs. For an elliptical slab of mass $=m_{\text {slab }}$, major axis equal to $l_{\text {slab }}$ and minor axis equal to $w_{\text {slab }}$, the moment of inertia of the slab is

$$
I_{\text {slab }}=\frac{1}{2} m_{\text {slab }}\left(l_{\text {slab }}^{2}+w_{\text {slab }}^{2}\right) .
$$

If the distance from the center of mass of the slab to the COR is $x_{\text {slab }}$, then, according to the parallel axis theorem,

$$
I_{\mathrm{H} / \mathrm{B}}=\sum_{i=1}^{S}\left(I_{\text {slab }}(i)+m_{\text {slab }}(i) x_{\text {slab }}(i)\right),
$$

where $S$ is the total number of modeled slices of the tadpole head/body.

The dimensions of the elliptical slabs were estimated from dorsal and ventral photographs of each tadpole. The depth of each slab $\left(d_{\text {slab }}\right)$ was $1 / 15$ the maximum depth of the head/body. The major axis of each slab was the length of the head/ body at the height of that slab. The minor axis of the slab was determined by assuming that the head/body had an elliptical horizontal profile and estimating the width of that ellipse at the height of the individual slab. Assuming constant density of $\rho \sim 1 \mathrm{~g} / \mathrm{cm}^{3}$, the center of mass of each slab is its geometric center, and $m_{\text {slab }}$ is $\rho$ divided by the slab volume,

$$
v_{\text {slab }}=\frac{1}{4} \pi d_{\text {slab }} w_{\text {slab }} l_{\text {slab }} .
$$

Maximum linear acceleration of the head/body is predicted by the ratio of the anatomical indicators of $F_{\text {muscle }}$ and $R_{\mathrm{a}}$ that is, the ratio of $\mathrm{CSA}_{\mathrm{mus}}: m_{\mathrm{H} / \mathrm{B}}$. Maximum rotational acceleration of the head/body is predicted by the ratio of the anatomical indicators of $T_{\text {muscle }}$ and $R_{\alpha}$, that is, the ratio of $\mathrm{CSA}_{\mathrm{mus}} X: I_{\mathrm{H} / \mathrm{B}}$.

\section{Animal protocol}

Protocols were approved by the University Committee on Use and Care of Animals of the University of Michigan. Wood frog, bullfrog, and American toad tadpoles were gathered as eggs, raised outdoors, and sampled periodically. Performance data were gathered via computer analysis of high-speed video of TSRs that were elicited in the laboratory. Morphological data were measured directly from tadpoles that were euthanized after performance trials and from dorsal and lateral photographs. I limited this analysis to a mass range where the three species overlapped $(0.032 \mathrm{~g} \leq$ tadpole mass $<0.185 \mathrm{~g})$. Samples consisted of wood frogs that were $0.032-0.184 \mathrm{~g}$, $1.43-2.71 \mathrm{~cm}$ and stages 26-30 (Gosner, '60), bullfrogs that were $0.037-0.147 \mathrm{~g}, 1.38-2.32 \mathrm{~cm}$ and stages 26-27, and American toads that were $0.034-0.183 \mathrm{~g}, 1.42-2.58 \mathrm{~cm}$ and stages $29-41$. 
Egg masses were collected in Washtenaw Co., MI. Five wood frog egg masses were gathered on April 3, 2003; two American toad egg masses were gathered on May 7, 2003; two bullfrog egg masses were gathered on June 10, 2003. Tadpoles were hatched and raised outdoors in 2361 pools (maximum density of 250 tadpoles/ pool/week). Tadpoles were fed ad libitum. Tadpoles in half of the pools were exposed to a chemical predator cue produced by Anax junius dragonfly naiads (3/pool) living in separate mesh cages and each fed approximately $800 \mathrm{mg}$ of live tadpoles (conspecific to tadpoles in the pool) per week $(2,400 \mathrm{mg} / \mathrm{pool})$. The purpose of the predator treatment was to attempt to induce the morphological variation natural to these populations (Van Buskirk and Relyea, '98), and the effect of this treatment (predator cue exposur$\mathrm{e}=\mathrm{PE}$, no predator cue exposure $=\mathrm{NPE}$ ) on tadpole performance was considered. Thus, samples consisted of $n_{\text {wood frog }}=29 \quad(\mathrm{PE}=13$, $\mathrm{NPE}=16), n_{\text {bullfrog }}=12(\mathrm{PE}=7, \mathrm{NPE}=5)$, and $n_{\text {toad }}=15 \quad(\mathrm{PE}=9, \quad \mathrm{NPE}=6) . \quad$ Tadpoles were transported into the laboratory and kept at $19^{\circ} \mathrm{C}$, the water temperature for the performance trials.

Digital images of artificially stimulated escape responses were filmed from a ventral view at 250 frames per second (Redlake Motionscope camera). I waited until tadpoles moved to the center of the experimental arena on their own volition. Escape responses were stimulated by a manual, dorsal poke to the BTI. When tadpole movement is not impeded by the grasp of the predator (as described in Johnson and Eidietis, 2005), the tadpole motions resemble those of TSRs elicited via contact with a blunt instrument under laboratory conditions (as in Azizi and Landberg, 2002; Fitzpatrick et al., 2003; Hale, '99). Up to five TSRs were induced within a $2 \mathrm{hr}$ period for wood frogs and American toads; the trial period was $4 \mathrm{hr}$ for bullfrogs, because bullfrogs moved to the center of the experimental arena less frequently.

Euthanized tadpoles were digitally photographed in dorsal and lateral views. Total tadpole mass $( \pm 0.001 \mathrm{~g})$ and Gosner ('60) developmental stage were determined. The tail was removed and $m_{\mathrm{H} / \mathrm{B}}( \pm 0.001 \mathrm{~g})$ was found. Head/body length (HL) and tail length (TL) were measured from lateral pictures (ImageJ v. 1.30 for Windows XP, W. Rasband: http://rsb.info.nih.gov/ij/) (Fig. 1). Tadpole length was calculated as the sum of HL and TL. The cross-sectional area of the tail muscle at the BTI $\left(\mathrm{CSA}_{\text {mus }}\right)$ was estimated from the muscle width (dorsal photographs) and muscle depth (lateral photographs).

\section{Acceleration measurements}

TSRs that were analyzed were at constant depth, with no rolling, and consisted of sequences with at least three large-amplitude tail motions. Cartesian coordinates $( \pm 0.001 \mathrm{~cm})$ of the BTI and nose were recorded from every frame of the digital video recordings (ImageJ). Filtering raw position data through a Butterworth fourth-order lowpass filter (Matlab 6.5 software) reduced the effects of digitizing and video jitter error (Walker, '98). COR was estimated as that point which moved least along an axis extending from the BTI to the nose, during the first two tail motions.

Maximum acceleration of COR $\left(a_{\max }\right)$ and maximum rotational acceleration $\left(\alpha_{\max }\right)$ of the head/ body during the time period defined by stages I and II were measured. I reported the time of $a_{\max }$ and $\alpha_{\max }$ as the amount of time elapsed after the initiation of head/body movement. Linear velocity was calculated from the difference in position coordinates between consecutive video frames. Linear acceleration was calculated as the difference between two consecutive calculations of velocity. All tadpoles were at rest for at least two video frames $(0.008 \mathrm{sec})$ before initiating the TSR movement. Thus, linear acceleration could be calculated for the first frame in which a tadpole showed a change in position. However, the measure of linear acceleration averaged over the first frame of motion was an underestimate for tadpoles which began acceleration during this $0.004 \mathrm{sec}$ interval. One wood frog trial was excluded from analyses of linear motion, because it was an extreme outlier and not representative of the central tendency of the species. The angle of the BTI-nose axis was defined as the head/body angle. Rotational velocity and acceleration of the head/body angle were calculated as explained for linear velocity and acceleration. Stage I was defined from the start of rotation of the head/body to the video frame before rotation reversed direction (Domenici and Blake, '97), that is, when rotational velocity reached zero. Stage II was defined as being from the time point when rotation reversed direction to the next point at which rotational velocity reached zero.

Maximum linear acceleration performance can be compromised if substantial rotational acceleration $(\alpha)$ occurs concurrently (Daniel and Meyhofer, '89), and, similarly, rotational acceleration 
performance may be comprised if substantial linear acceleration (a) occurs concurrently. To investigate this possibility, I calculated $\alpha$ at $a_{\max }$ and $a$ at $\alpha_{\max }$.

\section{Statistical analysis}

Statistical analyses were conducted using SPSS 11.5 for Windows XP unless otherwise noted. Null hypotheses were rejected at $P<0.05$.

I tested if kinematic parameters of the TSR differed between predator treatments. Several variables did not meet the assumptions of parametric analysis, and transformations did not successfully correct this problem. Therefore, I used a combination of techniques. First, I tested whether kinematic parameters co-varied with tadpole mass using Spearman's $\rho$ analysis. This analysis tests for the correlation of rankings and is appropriate for all variables. If correlation analysis showed no correlation with mass, and if the data were not normally distributed, I tested for differences in median values between treatments using a median test; these tests were conducted separately for each species. If data were normally distributed, I tested for differences between treatments using ANOVA, modeling treatment effects. When correlation analysis showed correlation with mass and the data were normally distributed, I tested for differences between treatments using ANCOVA, modeling treatment effects and treatment $\times$ mass effects. Treatment had no effect; therefore, I simplified further analysis by omitting this factor.

The angle rotated during stages I and II met parametric assumptions and showed no mass covariance; to test for interspecific differences, I used repeated-measures ANOVA. I tested for differences between stages I and II in angle rotated (within-subject effect), interspecific variation in the difference between stages I and II (stage $\times$ species interaction), and overall variation among species in angles rotated.

To test if either performance measurements $\left(a_{\max }\right.$ and $\left.\alpha_{\max }\right)$ or morphological indicators $\left(\mathrm{CSA}_{\mathrm{mus}}: m_{\mathrm{H} / \mathrm{B}}\right.$ and $\left.\mathrm{CSA}_{\text {mus }} X: I_{\mathrm{H} / \mathrm{B}}\right)$ were correlated with tadpole mass, I used linear regression of log transformed values. The log transformation reduced heteroscedasticity of error for use in later ANOVA and ANCOVA analysis (Zar, '96).

Because covariance with tadpole mass was rejected, ANOVA was used to test the hypotheses that $a_{\max }$ and $\alpha_{\max }$ differed among species, and Tahmane's pair-wise post hoc tests were used for species comparisons. ANCOVA was used to test the hypotheses that $\mathrm{CSA}_{\text {mus }}: m_{\mathrm{H} / \mathrm{B}}$ and CSAmus $\cdot X: I \mathrm{H} / \mathrm{B}$ differed among species, utilizing tadpole mass covariate. I compared the slopes of linear regressions of log transformed values using $t$-tests. I was unable to reject the null hypothesis of equal slopes; thus, I modeled the difference among species as the same at all masses (i.e., simple covariance). Bonferroni corrected pair-wise post hoc tests were used for species comparisons.

I tested if the anatomical indicators of the potential to linearly accelerate the head/body $\left(\mathrm{CSA}_{\mathrm{mus}}: m_{\mathrm{H} / \mathrm{B}}\right)$ and rotationally accelerate the head/body $\left(\mathrm{CSA}_{\text {mus }} X: I_{\mathrm{H} / \mathrm{B}}\right)$ correlated with the maximum linear and rotational acceleration $\left(a_{\max }\right.$ and $\alpha_{\max }$, respectively). Preliminary analyses indicated that the parametric Pearson's correlation and the Spearman's $\rho$ test provided consistent results. Because the goal of this investigation was to investigate if morphological indicators accurately rank tadpoles in terms of performance, Spearman's $\rho$ results are reported.

\section{RESULTS}

The specifics of the predator-exposure treatment are not detailed because it had no effect on kinematic parameters that were measured $(P>0.067$ for all responses tested).

\section{Description of the TSR}

The TSR consisted of two or more largeamplitude curls of the body, and the results presented here focus on the first two curls (i.e., stages I and II). The combined length of stages I and II of the TSR had a broad range, from 0.060 to $0.180 \mathrm{sec}$ (Table 2). During body curls, the head/ body rotated; the kinematics of the head/body motion fell along a spectrum bounded by motion in which the original orientation of the head/body was very close to the orientation at the end of stage II and motion in which these orientations formed a substantial angle $\geq 90^{\circ}$ (Fig. 2). During stage I, the COR either slipped or moved backwards, relative to the head/body long-axis (Fig. 2). Stage II motion was along a curve and typically lateral to head/body long axis (Fig. 2).

Tadpoles turned the head/body sharply during stage I (Table 2) and almost reversed that rotation during stage II (Table 2, Fig. 3); the rotation in stage II was $81 \%$ of the stage I rotation for wood frog tadpoles, 69\% of stage I rotation for bullfrogs, and $89 \%$ of stage I rotation for American toads (Fig. 3). The species differences were not 
TABLE 2. Kinematic parameters of the tactile-stimulated startle response

\begin{tabular}{llccc} 
Parameter & \multicolumn{1}{c}{ Species } & Median & Range & Mean \pm SEM \\
\hline Stage I: length (s) & Wood frog & 0.048 & $0.032-0.088$ \\
& Bullfrog & 0.032 & $0.020-0.064$ \\
& American toad & 0.040 & $0.032-0.072$ \\
Stage II: length (s) & Wood frog & 0.040 & $0.028-0.120$ \\
& Bullfrog & 0.058 & $0.040-0.092$ \\
Stage I: head/body angle rotated (degree) & American toad & 0.084 & $0.072-0.112$ \\
& Wood frog & 106.38 & $59.70-171.06$ & $107.89 \pm 6.15$ \\
& Bullfrog & 81.33 & $57.52-206.74$ & $91.27 \pm 11.47$ \\
Stage II: head/body angle rotated (degree) & American toad & 89.20 & $55.24-157.36$ & $99.05 \pm 8.65$ \\
& Wood frog & 81.44 & $12.91-160.63$ & $88.69 \pm 6.15$ \\
Stage I: COR distance traveled (cm) & Bullfrog & 62.43 & $18.27-120.68$ & $63.45 \pm 8.13$ \\
& American toad & 71.14 & $36.26-146.64$ & $82.237 \pm 8.59$ \\
& Wood frog & 0.20 & $0.10-0.71$ & $0.28 \pm 0.04$ \\
Stage II: COR distance traveled (cm) & Bullfrog & 0.16 & $0.09-0.37$ & $0.17 \pm 0.02$ \\
& American toad & 0.22 & $0.06-0.72$ & $0.25 \pm 0.05$
\end{tabular}

Average values are reported for normally distributed data with no mass covariance. Medians and ranges are reported for all data. Sample sizes are, for woodfrog (Rana sylvatica), $n=29$; for bullfrog (Rana catesbeiana), $n=12$; for American toad (Bufo americanus), $n=19$.

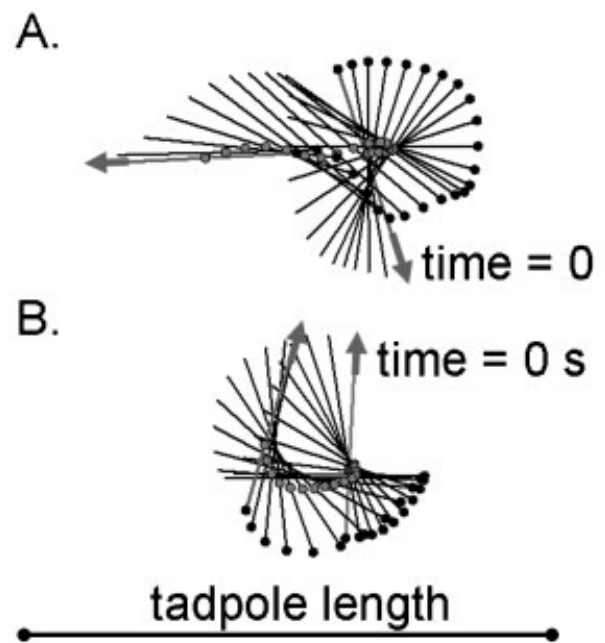

Fig. 2. Two extremes of a spectrum of head/body movement patterns exhibited by wood frog (Rana sylvatica), bullfrog (Rana catesbeiana), and American toad (Bufo americanus) tadpoles over the course of a tactile-stimulated startle response (TSR) are illustrated. The orientation of the head/ body is illustrated at $0.004 \mathrm{sec}$ intervals. Black dots represent the BTI. Gray arrows indicate the starting orientations and orientations at the end of stage II of the TSR. (A) The orientation at the end of stage II is almost perpendicular to the original orientation. (B) The orientation at the end of stage II is almost equal to that at the start of stage I.

significant; repeated-measures ANOVA indicated a lack of species effect both on the difference between the angles in stages I and II (stagespecies interaction, $P>0.7$ ) and on the overall

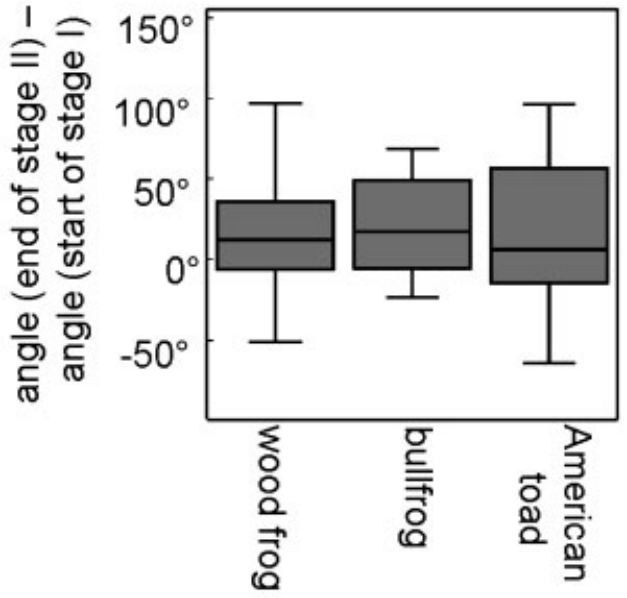

Fig. 3. The change in the orientation of the head/body from the start of stage I to the end of stage II of the tactilestimulated startle responses is shown for wood frog $(n=29)$, bullfrog $(n=12)$, and American toad $(n=15)$ tadpoles. Medians (horizontal lines), 50\% (boxes) and 75\% (bars) quartiles are shown.

magnitude of angles rotated (species effect, $P>0.56)$.

Tadpoles did not travel far during stages I and II, relative to their body length. The distance traveled in stage I (Table 2 ) was only $12.6 \pm 7.8 \%$ (mean \pm SD) of length. The distance traveled in stage II (Table 2) was only $26.0 \pm 7.9 \%$ (mean $\pm \mathrm{SD}$ ) of length. 
Maximum acceleration occurred immediately for most tadpoles. Between the last video frame when tadpoles were at rest and the first frame of movement, tadpoles accelerated to an initial velocity. This immediate velocity increase was $\alpha_{\max }$ for many tadpoles: $72 \%$ of wood frogs, $42 \%$ of bullfrogs, and $80 \%$ of American toads showed $\alpha_{\max }$ in the first $0.004 \mathrm{sec}$ of motion (Fig. 4). Fewer tadpoles (34\% of wood frogs, $17 \%$ of bullfrogs, $33 \%$ of American toads) showed $a_{\max }$ in the first $0.004 \mathrm{sec}$ (Fig. 4). All tadpoles showed $a_{\max }$ and $\alpha_{\max }$ within $0.12 \mathrm{sec}$ of motion. It was impossible to

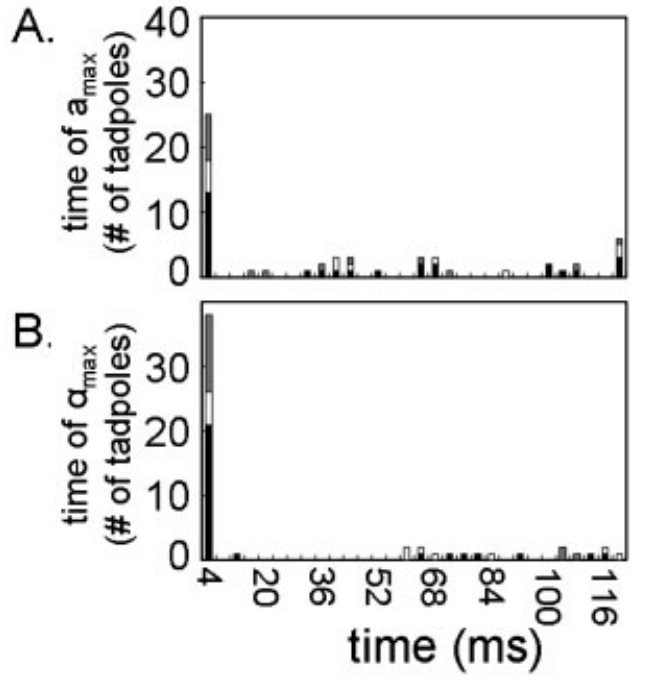

Fig. 4. The time, during a TSR, of maximum linear acceleration $\left(a_{\max }\right)(\mathbf{A})$ and maximum rotational acceleration $\left(\alpha_{\max }\right)(\mathbf{B})$ for three species of tadpoles is indicated by bars. Time began with the initiation of movement of the head/body. Wood frog is black $(n=29)$; bullfrog is white $(n=12)$; American toad is gray $(n=15)$. determine when the tadpoles began to accelerate during the initial $0.004 \mathrm{sec}$ frame interval. Therefore, $a_{\max }$ and $\alpha_{\max }$ calculated at $0.004 \mathrm{sec}$ are likely underestimates for some tadpoles.

Tadpoles were, for the most part, simultaneously linearly and rotationally accelerating the head/body at the time when $a_{\max }$ and $\alpha_{\max }$ occurred. At the time of $a_{\max }, \alpha$ was non-zero for $79 \%$ of wood frogs, $75 \%$ of bullfrogs, and $80 \%$ of American toads. At the time of $\alpha_{\max }, a_{\mathrm{COR}}$ was non-zero for all tadpoles.

\section{Acceleration performance}

Acceleration did not vary with tadpole mass, as indicated by a lack of significance of linear regressions for all three species (Table 3).

Overall, bullfrog tadpoles had greater maximum acceleration performance than did the other species (Fig. 5C). Bullfrog had higher $a_{\max }$ than wood frog (ANOVA with pair-wise test, $P<0.017$ ) (Fig. 5C, Tables 4 and 5). Bullfrog $a_{\max }$ was greater than that of American toad tadpoles (Fig. 5C, Table 4), but this difference was not statistically significant (pair-wise test, $P>0.057$ ). Wood frog and American toad did not show a difference in $a_{\max }$ (pair-wise test, $P>0.990$ ) (Fig. $5 \mathrm{C}$, Table 4). Bullfrog tadpoles showed higher $\alpha_{\max }$ than American toad (ANOVA with pair-wise test, $P<0.035$ ) (Fig. 5C, Tables 4 and 5). No other interspecific differences were significant (pairwise tests: $P>0.130$ for bullfrog and wood frog comparison, $P>0.561$ for wood frog and American toad comparison).

TABLE 3. Linear regression modeling of the covariance of mass and anatomical indicators of acceleration capacity and mass and acceleration performance

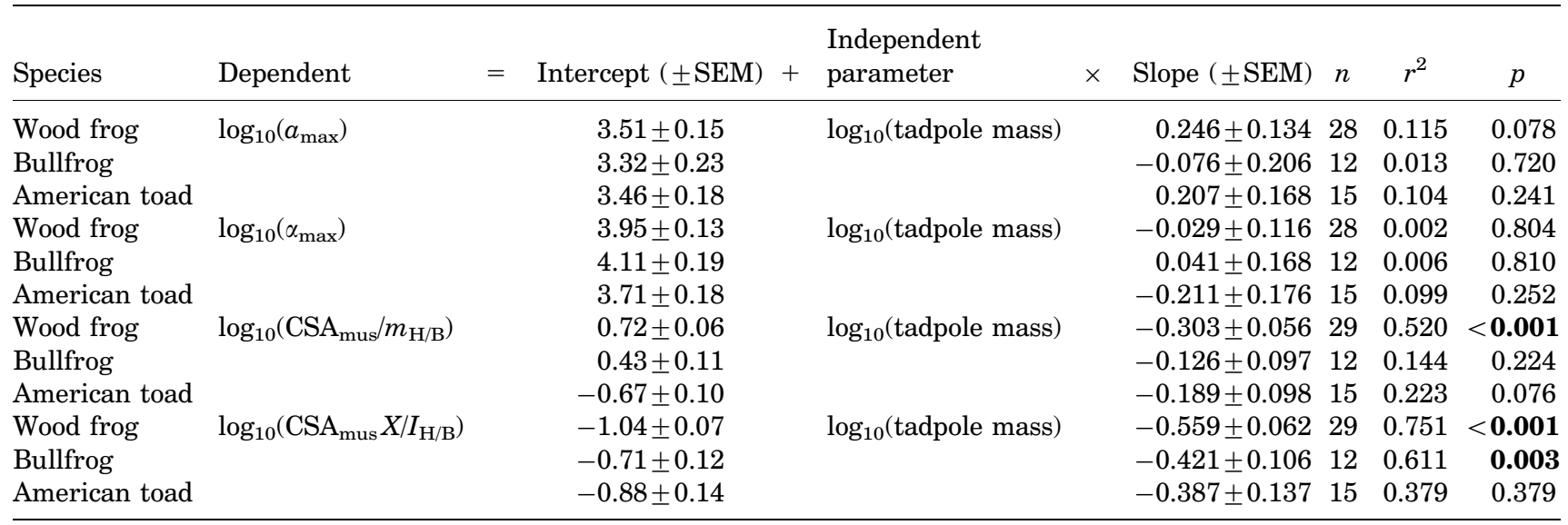

Units are g, cm, s. Bold indicates statistically significant relationships. 
A.

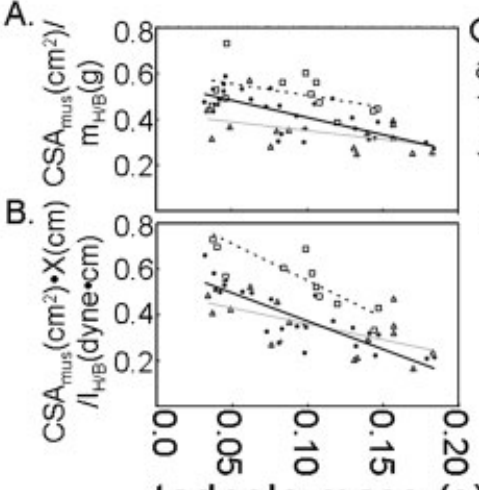

tadpole mass $(\mathrm{g})$

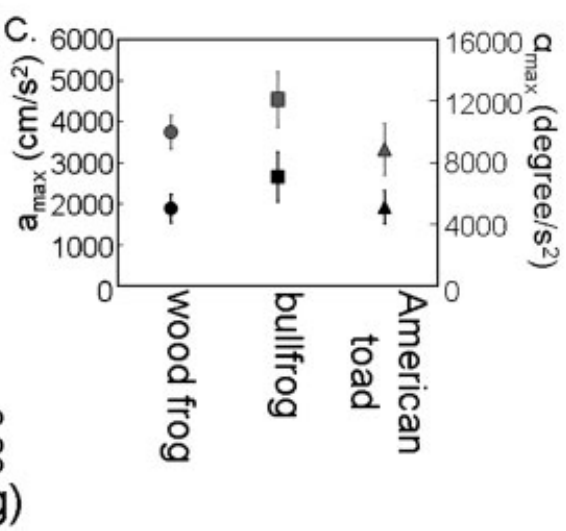

Fig. 5. (A and B) Anatomical indicators of performance potential and (C) measurements of maximum linear acceleration of the head/body $\left(a_{\max }\right.$, black) and maximum rotational acceleration of the head/body ( $\alpha_{\max }$, gray) are graphed for wood frog (circles, $n=28$ ), bullfrog (squares, $n=12$ ), and American toad (triangles, $n=15$ ) tadpoles.

TABLE 4. Maximum acceleration performance during the tactile-stimulated startle response

\begin{tabular}{llccc}
\hline Parameter & Species & Median & Range & Mean \pm SEM \\
\hline $\begin{array}{l}\text { COR maximum linear } \\
\text { acceleration }\left(\mathrm{cm} / \mathrm{s}^{2}\right)\end{array}$ & Wood frog & 1672.71 & $1014.24-5489.82$ & $1,886.85 \pm 172.15$ \\
& Bullfrog & 2363.17 & $1617.20-5489.82$ & $2,657.27 \pm 302.77$ \\
& American toad & 1775.74 & $1178.14-3579.21$ & $1,920.37 \pm 201.97$ \\
Maximum head/body & Wood frog & 10075.00 & $4537.50-16168.75$ & $9,982.54 \pm 543.94$ \\
$\quad$ rotational acceleration $\left(\% / \mathrm{s}^{2}\right)$ & & & & \\
& Bullfrog & 12624.54 & $7168.75-17493.75$ & $12,092.63 \pm 894.92$ \\
& American toad & 8587.50 & $4312.50-15106.25$ & $8,871.25 \pm 834.20$ \\
\hline
\end{tabular}

Wood frog $(n=29)$, bullfrog $(n=12)$, and American toad $(n=19)$.

TABLE 5. Interspecific variation in acceleration performance and anatomical indicators of performance potential

\begin{tabular}{llrc}
\hline \multirow{2}{*}{ Dependent } & $\begin{array}{c}\text { Source of } \\
\text { variance }\end{array}$ & \multicolumn{1}{c}{$F_{\mathrm{df}}$} & $P$ \\
\hline $\log _{10}\left(a_{\text {max }}\right)$ & Model & $4.395_{2}$ & $\mathbf{0 . 0 1 7}$ \\
& Intercept & $20467.333_{1}$ & $\mathbf{0 . 0 0 0}$ \\
& Species & $4.395_{2}$ & $\mathbf{0 . 0 1 7}$ \\
$\log _{10}\left(\alpha_{\text {max }}\right)$ & Corrected & $3.711_{2}$ & $\mathbf{0 . 0 3 1}$ \\
& Model & & \\
& Intercept & $38778.164_{1}$ & $\mathbf{0 . 0 0 0}$ \\
& Species & $3.711_{2}$ & $\mathbf{0 . 0 3 1}$ \\
$\log _{10}\left(\mathrm{CSA}_{\text {mus }} / m_{\mathrm{H} / \mathrm{B}}\right)$ & Model & $22.373_{3}$ & $\mathbf{0 . 0 0 0}$ \\
& Intercept & $167.846_{1}$ & $\mathbf{0 . 0 0 0}$ \\
& log $(\mathrm{M})$ & $27.794_{1}$ & $\mathbf{0 . 0 0 0}$ \\
& Species & $15.499_{2}$ & $\mathbf{0 . 0 0 0}$ \\
$\log _{10}\left(\mathrm{CSA}_{\text {mus }} X / I_{\mathrm{H} / \mathrm{B}}\right)$ & Model & $41.261_{3}$ & $\mathbf{0 . 0 0 0}$ \\
& Intercept & $225.717_{1}$ & $\mathbf{0 . 0 0 0}$ \\
& $\log _{10}(\mathrm{M})$ & $77.867_{2}$ & $\mathbf{0 . 0 0 0}$ \\
& Species & $19.226_{1}$ & $\mathbf{0 . 0 0 0}$ \\
\hline
\end{tabular}

Bold indicates a significant effect.

\section{Morphological variation}

Both $\mathrm{CSA}_{\text {mus }}: m_{\mathrm{H} / \mathrm{B}}$ and $\mathrm{CSA}_{\text {mus }} X: I_{\mathrm{H} / \mathrm{B}}$ increased with tadpole mass (Fig. 5A and B; Tables 3 and 5).

The interspecific ranking for the ratio of $\mathrm{CSA}_{\text {mus }}: m_{\mathrm{H} / \mathrm{B}}$ (i.e., the morphological indicator of linear acceleration potential) was bullfrog $>$ wood frog $>$ American toad (Fig. 5A). This result was supported by ANCOVA modeling (pair-wise tests: $P<0.013$ ) (Table 5).

The interspecific ranking for the ratio $\mathrm{CSA}_{\text {mus }}$ $X: I_{\mathrm{H} / \mathrm{B}}$ (i.e., the morphological indicator of rotational acceleration potential) was bullfrog $>$ wood frog $=$ American toad. This result was supported by ANCOVA (Table 5). Bullfrog had the highest $\mathrm{CSA}_{\text {mus }} X: I_{\mathrm{H} / \mathrm{B}}$ (pair-wise test, $P<0.001$ ) (Fig. 5B). Wood frog and American toad did not differ in $\mathrm{CSA}_{\text {mus }} X: I_{\mathrm{H} / \mathrm{B}}(P>0.9)$ (Fig. 5B).

The anatomical indicators did not effectively rank the maximum acceleration performance of 
TABLE 6. No rank correlation of anatomical indicators of performance potential and acceleration performance

\begin{tabular}{lllr} 
Bivariate pair & \multicolumn{1}{c}{ Sample } & $n$ & Spearman's coefficient $(P)$ \\
\hline $\log _{10}\left(\mathrm{CSA}_{\text {mus }} / m_{\mathrm{H} / \mathrm{B}}\right)$ and $\log _{10}\left(a_{\text {max }}\right)$ & Combined species & 55 & $-0.030(0.829)$ \\
& Wood frog & 28 & $-0.154(0.433)$ \\
& Bullfrog & 12 & $-0.441(0.152)$ \\
$\log _{10}\left(\mathrm{CSA}_{\mathrm{mus}} X / I_{\mathrm{H} / \mathrm{B}}\right)$ and $\log _{10}\left(\alpha_{\text {max }}\right)$ & American toad & 15 & $-0.332(0.226)$ \\
& Combined species & 56 & $0.122(0.369)$ \\
& Wood frog & 28 & $-0.043(0.825)$ \\
& Bullfrog & 12 & $-0.343(0.276)$ \\
& American toad & 15 & $0.114(0.685)$ \\
\hline
\end{tabular}

individual tadpoles (Table 6), as the morphological indicator of linear acceleration capacity (CSAmus: $m \mathrm{H} / \mathrm{B})$ and rotational acceleration capacity $\left(\mathrm{CSA}_{\text {mus }} X: I_{\mathrm{H} / \mathrm{B}}\right)$ did not correlate with $a_{\max }$ or $\alpha_{\max }$, respectively (Table 6 ). This lack of correlation was true both within individual species and for a combined sample (Table 6).

The anatomical indicators of acceleration performance capacity were more informative in ranking the species' averages of realized maximum performance. The averages of $\mathrm{CSA}_{\mathrm{mus}}: m_{\mathrm{H} / \mathrm{B}}$ for the species correctly predicted that bullfrog would have greater average $a_{\max }$ than wood frog and American toad (Fig. 5A, C). However, the more subtle difference between wood frog and American toad average $\mathrm{CSA}_{\text {mus }}: m_{\mathrm{H} / \mathrm{B}}$ (Fig. $5 \mathrm{~A}$ ) was not reflected in the linear acceleration performance (Fig. 5C). The average $\mathrm{CSA}_{\text {mus }} X: I_{\mathrm{H} / \mathrm{B}}$ for the species correctly predicted that bullfrog would have the highest average $\alpha_{\max }$ (Fig. 5B). However, a corresponding interspecific difference in performance was only significant for the bullfrog and American toad comparison. The more subtle difference between bullfrog and wood frog tadpoles that was predicted by $\mathrm{CSA}_{\text {mus }} X: I_{\mathrm{H} / \mathrm{B}}$ (Fig. 5B) was not reflected in the statistical tests of among-species differences in $\alpha_{\max }$ (Fig. 5C).

\section{DISCUSSION}

\section{Summary of results}

In order to contextualize acceleration performance, I described the kinematic parameters of the TSRs of wood frog, bullfrog, and American toad tadpoles. This description revealed that these tadpoles showed a spectrum of kinematic patterns (Fig. 2). Below, I discuss this result in terms of possible proximal causes.

I also asked whether species differed in maximum acceleration performance during the TSR. Bullfrog tadpoles showed an overall higher performance of linear and rotational acceleration of the head/body. Bullfrogs also had anatomical differences from the other two species that predicted this interspecific variation in performance. This suggests that the morphological indicators quantified in this analysis may be useful for interpreting ecomorphological patterns of pond community structure. However, these results were not clear cut: wood frog and American toad tadpoles had anatomical differences but no significant performance differences. In addition, the intraspecific variation in morphology was not predictive of within-species performance, despite substantial variation in both anatomy and performance. I discuss the utility of these results in light of this ambiguity.

\section{Kinematics}

As reported previously (Hoff, '88), tadpoles exhibited various patterns of motion during TSRs. The head/body motions that were associated with extremes of these patterns are illustrated in Figure 2. In most cases, the head/body almost completely returned to its original orientation by the end of stage II. However, in many cases, the orientation at the end of stage II was different from the original. In a previous study encompassing a broader size range of wood frog tadpoles, I showed a similar pattern: the average rotation of wood frog head/body during stage I was $130^{\circ}$ and, during stage II, rotation averaged $113^{\circ}$, almost reversing stage I rotation (Eidietis, 2005). The median head/body orientation at the end of stage II was very close to the original orientation (Fig. 3), suggesting that this type of response ("double c" Hoff, '88) may be most representative. This kinematic pattern of the startle response distinguishes tadpole responses from C-starts of other vertebrates. In the typical fish or salamander (Bennett et al., '89; Azizi and Landberg, 2002; 
Fitzpatrick et al., 2003) C-start, stage I includes a curl into a $\mathrm{C}$, but, in stage II, the head does not rotate as substantially and the body deformation is more akin to a J (Weihs, '72; Domenici and Blake, '97). The prominence of the "double C" type of TSR is descriptive evidence that, though the anuran tadpole TSR likely shares an evolutionary origin with fast-starts of other vertebrates (reviewed in Hale et al., 2002), kinematics differ.

Also, unlike fish and salamander fast-starts, the tadpole TSR did not propel the tadpole along the head/body longitudinal axis. Even when the head/ body showed movement during stage II, much of this movement was slip, rather than straight, translational motion (Fig. 2A). In fact, even after the initial stages of the TSR, tadpole burst swimming includes several changes in the head/ body orientation (Feder, '83; Van Buskirk and McCollum, 2000). A change in head/body orientation without a coincident change in COR direction results in slip. Thus, slip may be ubiquitous when tadpoles are moving vigorously. In contrast, for fish (Weihs, '72; Domenici and Blake, '97) and larval (Azizi and Landberg, 2002; Fitzpatrick et al., 2003) and adult (Azizi and Landberg, 2002) salamanders, the fast-start stage II propels the animal forward along the longitudinal axis. For this reason, Weihs ('72) suggested that stage I be considered "preparatory" for the propulsion in stage II. From published video sequences and tracings of fish and salamander fast-starts (e.g., Domenici and Blake, '97; Fitzpatrick et al., 2003), it is clear that the propulsion of these animals during stage II is translational (not slip).

Why do the kinematic patterns of escape responses differ among these taxa? Recent investigation of fish fast-starts indicates that kinematics and performance result from a dynamic balance between the force of axial muscle contraction and the hydrodynamic resistance to motion (Wakeling and Johnston, '98; Wakeling, 2001; Goldbogen et al., 2005). A tadpole has very different morphology from most fishes and salamanders, and, thus, a different distribution of resistance. Rather than being elongated bodies, tadpoles have a large, bulbous mass (i.e., the head/ body) attached to a laterally flattened tail. Thus, for a tadpole, a large portion of the resistance in the anterior body is inertial resistance of the body itself, as opposed to hydrodynamic resistance. This distribution qualitatively differs from aquatic salamanders and many fishes that have been used as model organisms for the study of fast-starts (e.g., Webb, '82; Wakeling, 2001; Azizi and
Landberg, 2002; Fitzpatrick et al., 2003; Goldbogen et al., 2005). Moreover, unlike many fish species, tadpoles do not have a major source of hydrodynamic resistance at the posterior end of the body (i.e., the fish tailfin). Instead, most of the laterally flattened area on the tadpole is at the anterior half of the tail (Hoff, '88) (Fig. 1). In sum, the distribution of resistance of a tadpole is very different from the distribution of resistance of a fish.

Differing distributions of resistance may lead to differing patterns of deformations and kinematics. Much of that propulsion of the fish and salamander fast-start (Weihs, '72; Webb, '78; Domenici and Blake, '97; Azizi and Landberg, 2002; Fitzpatrick et al., 2003, etc.)stems from high-amplitude motions of the posterior tail fin. In fish, the angle of attack of the fin is such that most of the force generated by this motion is directed posteriorly (Weihs, '72), pushing the animal forward. Tadpoles lack a large posterior tail fin (Fig. 1). This body morphology, interacting with TSR body deformations, may cause most of the force produced by the tail to be lateral, as in eel locomotion (Tytell and Lauder, 2004), rather than directed in a single, useful (for translation) direction.

\section{Intraspecific variation in acceleration performance}

In the current study, bullfrogs showed greater maximum acceleration performance than wood frogs and American toads, an interspecific difference proximately explained by the balance of the capacity to produce force and the resistance to acceleration. However, there was no intraspecific correlation between this balance and the acceleration performance. This combination of interspecific correlation of morphology and performance but not intraspecific correlation can be explained by random effects of branching phylogenetic histories (Felsenstein, '85), irrespective of functional correlation. Though possible, this explanation is unlikely for the results presented here. First, the more closely related ranid species (Ford and Cannatella, '93) do not cluster together (Fig. 5) as would be expected under the null hypothesis that the correlation of morphological indicators and acceleration performance is explained by phylogenetic effects (Felsenstein, '85). Second, I presented an a priori biomechanical hypothesis explaining how bullfrog tadpoles outperformed wood frog and American toad tadpoles. Though it is possible that random phylogenetic 
effects could coincidently match the biomechanical model, this seems unlikely. Nonetheless, similar analyses utilizing sister species would contribute towards eliminating the suspicion that phylogeny, rather than biomechanical function, explains the interspecific patterns seen in Figure 5.

These species live across a habitat spectrum that is defined partially by the level and type of predation (Wellborn et al., '96; Richardson, 2002). Habitats that include fish typically do not support wood frog or American toad tadpoles (Collins and Wilbur, '79). There are several functional hypotheses explaining the species assemblages of tadpoles in different predation environments. Non-locomotor explanations include oviposition site choice (Hopey and Petranka, '94; Petranka et al., '94), interspecific differences in levels of activity (Kats et al., '88; Werner, '91), and the existence of chemical defenses against specific predators (Kats et al., '88). The current data show that bullfrogs outperform wood frogs and American toads in terms of maximum acceleration during the TSR. Bullfrogs also differ from these species in habitat type (Collins and Wilbur, '79; Richardson, 2002). This raises the question of whether acceleration performance may be a proximal cause of the assemblage structuring reported for pond communities.

At the spatial and temporal scale of a predator strike, it is unlikely that maximum acceleration in the initial instant of the TSR is less important to wood frog and American toad survival than it is to bullfrog survival. Tadpoles tend not to initiate TSRs until contacted (Pritchard, '65; Van Buskirk and McCollum, 2000; Zottoli et al., 2001; Teplitsky et al., 2005; Johnson and Eidietis, in press). Breaking contact is initially a matter of quickly accelerating before the predator fully gains control of tadpole movement (Figiel and Semlitsch, '91; Johnson and Eidietis, 2005). All species' tadpoles most probably benefit from a greater ability to move out of contact with a predator before the predator gains control of tadpole motion.

However, after initial contact with a predator, a tadpole must move out of the predator's range or risk being attacked again. Except when starved (Altwegg, 2003), invertebrate predators seldom chase prey (Pritchard, '65; Folsom and Collins, '84; Formanowicz, '87; Johnson and Eidietis, in press). Bullfrog tadpoles experience key differences in predation pressure. They encounter piscine predators (Collins and Wilbur, '79; Werner, '91; Werner and McPeek, '94) that are much more likely to give chase than the grasping and piercing invertebrate predators of smaller and temporary ponds inhabited by wood frogs and American toads (Collins and Wilbur, '79). The morphological indicators of high acceleration performance are also likely to increase prey sprint speed and maneuverability during chases (Brown and Taylor, '95; Watkins, '96; Teplitsky et al., 2005): a relatively high ratio of force production capability to inertial resistance is likely to increase burst swimming speed and a high ratio of torque production capability to moment of inertia may increase maneuverability One interesting avenue for future research would be to test if acceleration performance is correlated with other measures of performance, such as sprint speed.

\section{Relationship between anatomy and performance}

The prediction made from simple physical analysis of tadpole anatomical indicators of force and torque capacity and resistance to acceleration ranked species' average maximum accelerations fairly accurately. As predicted, bullfrogs had both the greatest linear and rotational acceleration performance, while wood frogs and American toads have lower acceleration performance. However, the finer distinctions predicted between wood frog and American toad tadpoles were not shown by performance data. Also, this gross anatomical approach was not successful in predicting the performance ranking of individual tadpoles. Given the level of reliability shown in this study, this method seems best suited to broad ranking of abilities of anatomically disparate taxa (Webb, '78, 84). This sample of anuran tadpole species is extremely conservative in terms of the known anatomical diversity (see Altig and McDiarmid, '99). Thus, the level of success in ranking species' acceleration abilities shown here suggests that the current approach is sufficient for estimating relative interspecific acceleration ability over a more representative sample of anuran species.

Would a less coarse analysis of tadpole anatomy and morphology allow for better prediction of intraspecific or interspecific variation in performance? Attempts to seek correlations between aquatic amphibian form and performance of escape responses have met with mixed success. Most studies focus not on the first two stages of the TSR, but on swimming performance in a burst swim after these initial stages. In a comparative study of 14 species of North American anuran 
tadpoles, Richardson (2002) shows no evidence of covariance between tadpole morphology and swim speed, though swim speed is affected by tail beat frequency. Similarly, aquatic salamanders (Ambystoma tigrinum) show no correlation between differences in body form and swimming performance (Bennett et al., '89; Azizi and Landberg, 2002). In fact, Bennet et al. ('89) do not even show a correlation between swim speed and muscle contractile properties. In contrast, a single species sample of Hyla versicolor tadpoles does show correlation among gross morphological form and swimming performance (Van Buskirk and McCollum, 2000). However, the Bennet et al. ('89) salamander study and Van Buskirk's and McCollum's (2000) anuran tadpole study do not control for tail beat frequency or statistically consider tail beat frequency as a possible covariate of the effect of form. This may be a critical factor, as Fitzpatrick et al. (2003) report that performance of salamander larvae (A. tigrinum) fast-starts is the result of an interaction among larval morphology, physiology, and behavior (where one primary quantification of behavior was tail beat frequency). When, as during a predator strike, a predator and prey are in close proximity, the behavioral choices of the predator and prey are limited, and failure has direct mortal (and, hence, fitness) consequences (Webb, '86). Given such limitation to the freedom for variation in behavior, it is expected that the connection between morphology and performance may best be understood within interactions of this fine spatial-temporal scale. Despite the spatial and temporal proximity of predators during the TSR; however, current research suggests that anuran larvae show substantial variability in behavior (i.e., kinematics of the TSR) (Hoff, '88; Richardson, 2002, current results). When such variability in behavior exists, the connection between morphology and performance may not be clear. This is seen in the current lack of intraspecific correlation between a morphological indicator of acceleration capacity and acceleration performance.

\section{ACKNOWLEDGMENTS}

Thanks to Paul Webb for guidance and Mara Zimmerman for comments on this manuscript. Thanks to Brady West for help on statistical analysis. This research was supported by National Science Foundation Grant IBN 9973942 (to P. Webb). Thanks to James Gapczynski for help with collections and the Pinckney Recreation Area
(Washtenaw Co., Michigan), Independence Lake County Park (Washtenaw Co.), and the Michigan Department of Natural Resources Institute for Fisheries Research Station (Saline, MI) for permission to collect. Animals were collected under a collector's permit issued by the Michigan Department of Natural Resources (to L. Eidietis).

\section{LITERATURE CITED}

Altig R, McDiarmid RW. 1999. Diversity: familial and generic characterizations. In: McDiarmid RW, Altig R, editors. Tadpoles: the biology of anuran larvae. Chicago: The Unversity of Chicago Press. p 295-337.

Altwegg R. 2003. Hungry predators render predator-avoidance behavior in tadpoles ineffective. Oikos 100:311-316.

Azizi E, Landberg T. 2002. Effects of metamorphosis on the aquatic escape response of the two-lined salamander (Eurycea bislineata). J Exp Biol 205:841-849.

Bennett AF, Garland TJ, Else PL. 1989. Individual correlation of morphology, muscle mechanics, and locomotion in a salamander. Am J Physiol 256 (Regul Integr Comp Physiol 25):R1200-R1208.

Blair J, Wassersug RJ. 2000. Variation in the pattern of predator-induced damage to tadpole tails. Copeia 2000: 390-401.

Brennen CE. 1982. A review of added mass and fluid inertial forces. Port Hueneme, CA: Naval Civil Engineering Laboratory. Report no. CR 82.010, 50p.

Brown RM, Taylor DH. 1995. Compensatory escape mode trade-offs between swimming performance and maneuvering behavior through larval ontogeny of the wood frog, Rana sylvatica. Copeia 1995:1-7.

Carroll AM, Wainwright PC, Huskey SH, Collar DC, Turingan RG. 2004. Morphology predicts suction feeding performance in centrarchid fishes. J Exp Biol 207:3873-3881.

Collins JP, Wilbur HM. 1979. Breeding habits and habitats of the amphibians of the Edwin S. George Reserve, Michigan, with notes on the local distribution of fishes. Occas Pap Mus Zool, Univ Mich 686:1-34.

Daniel TL. 1984. Unsteady aspects of aquatic locomotion. Am Zool 24:121-134.

Daniel TL. 1985. Cost of locomotion: unsteady medusan swimming. J Exp Biol 119:149-164.

Daniel TL, Meyhofer E. 1989. Size limits in escape locomotion of carridean shrimp. J Exp Biol 143:245-265.

Denny MW. 1993. Air and water: the biology and physics of life's media. Princeton, NJ: Princeton University Press.

Doherty PA, Wassersug RJ, Lee JM. 1998. Mechanical properties of the tadpole tail fin. J Exp Biol 201:2691-2699.

Domenici P, Blake RW. 1997. The kinematics and performance of fish fast-start swimming. J Exp Biol 200: 1165-1178.

Eidietis L. 2005. Size-related performance variation in the woodfrog (Rana sylvatica) tadpole tactile-stimulated startle response. Can J Zool 83:1117-1127.

Feder ME. 1983. The relation of air breathing and locomotion to predation on tadpoles, Rana berlandieri, by turtles. Physiol Zool 56:522-531.

Felsenstein J. 1985. Phylogenies and the comparative method. Am Nat 125:1-15. 
Figiel CRJ, Semlitsch RD. 1991. Effects of nonlethal injury and habitat complexity on predation in tadpole populations. Can J Zool 69:830-834.

Fitzpatrick BM, Benard MF, Fordyce JA. 2003. Morphology and escape performance of tiger salamander larvae (Ambystoma tigrinum mavortium). J Exp Zool 297A: 147-159.

Folsom TC, Collins NC. 1984. The diet and foraging behavior of the larval dragonfly Anax junius (Aeshnidae), with an assessment of the role of refuges and prey activity. Oikos 42:105-113.

Ford LS, Cannatella DC. 1993. The major clades of frogs. Herpetol Monogr 7:94-117.

Formanowicz DRJ. 1987. Foraging tactics of Dytiscus verticalis larvae (Coleoptera, Dytiscidae)-Prey detection, reactive distance and predator size. J Kan Ent Soc 60: 92-99.

Gee JH, Waldick RC. 1995. Ontogenetic buoyancy changes and hydrostatic control in larval anurans. Copeia 1995: 861-870.

Goldbogen JA, Shadwick RE, Fudge DS, Gosline JM. 2005. Fast-start dynamics in the rainbow trout Oncorhynchus mykiss: phase relationship of white muscle shortening and body curvature. J Exp Biol 208:929-938.

Gosner KL. 1960. A simplified table for staging anuran embryos and larvae with notes on identification. Herpetologica 16:183-190.

Hale ME. 1999. Locomotor mechanics during early life history: effects of size and ontogeny on fast-start performance of salmonid fishes. J Exp Biol 202:1465-1479.

Hale MH, Long JH, McHenry MJ, Westneat MW. 2002. Evolution of behavior and neural control of the fast-start escape response. Evolution 56:993-1007.

Hoff KvS. 1988. Morphological determinants of fast-start performance in anuran tadpoles. Dissertation, Dalhousie University.

Hopey ME, Petranka JW. 1994. Restriction of wood frogs to fish-free habitats: how important is adult choice? Copeia 1994:1023-1025.

Johansson LC. 2003. Indirect estimates of wing-propulsion forces in horizontally diving Atlantic puffins (Fratercula artica L.). Can J Zool 81:816-822.

Johnson KE, Eidietis L. 2005. Tadpole body zones differ in dragonfly naiad strike frequencies and kill rates. Copeia 2005:908-912.

Kats LB, Petranka JW, Sih A. 1988. Antipredator defenses and the persistence of amphibian larvae with fishes. Ecology 69:1865-1870.

Larson PM. 2005. Ontogeny, phylogeny, and morphology in Anuran larvae: morphometric analysis of cranial development and evolution in Rana tadpoles (Anura: Ranidae). J Morphol 264:34-52.

Morin PJ. 1985. Predation intensity, prey survival and injury frequency in an amphibian predator-prey interaction. Copeia 1985:638-644.

Petranka JW, Hopey ME, Jennings BT, Baird SD, Boone SJ. 1994. Breeding habitat segregation of wood frogs and American toads: the role of interspecific tadpole predation and adult choice. Copeia 1994:691-697.

Pritchard G. 1965. Prey capture by dragonfly larvae (Odonata; Anisoptera). Can J Zool 43:271-289.

Richardson JML. 2002. Burst swim speed in tadpoles inhabiting ponds with different top predators. Evol Ecol Res 4: 627-642.
Seger J, Stubblefield JW. 1996. Optimization and adaptation. In: Lauder GV, editor. Adaptation. New York: Academic press. p 93-123.

Teplitsky C, Plenet S, Lena J-P, Mermet N, Malet E, Joly P. 2005. Escape behaviour and ultimate causes of specific induced defences in an anuran tadpole. J Evol Biol 18: 180-190.

Tytell ED, Lauder GV. 2004. The hydrodynamics of eel swimming: I. Wake structure. J Exp Biol 207: 1825-1841.

Van Buskirk J, McCollum SA. 2000. Influence of tail shape on tadpole swimming performance. J Exp Biol 203:2149-2158.

Van Buskirk J, Relyea RA. 1998. Selection for phenotypic plasticity in Rana sylvatica tadpoles. Biol J Linn Soc 65: 301-328.

Van Buskirk J, Anderwald P, Lupold S, Reinhardt L, Schuler H. 2003. The lure effect, tadpole tail shape, and the target of dragonfly strikes. J Herpetol 37:420-424.

Van Buskirk J, Aschwanden J, Buckelmuller I, Reolon S, Ruttiman S. 2004. Bold tail coloration protects tadpoles from dragonfly strikes. Copeia 2004:599-602.

Wainwright PC, Bellwood DR, Westneat MW. 2002. Ecomorphology of locomotion in labrid fishes. Environ Biol Fishes 65:47-62.

Wakeling JM. 2001. Biomechanics of fast-start swimming in fish. Comp Biochem Physiol A 131:31-40.

Wakeling JA, Johnston IA. 1998. Muscle power output limits fast-start performance in fish. J Exp Biol 201:1505-1526.

Walker JA. 1998. Estimating velocities and accelerations of animal locomotion: a simulation experiment comparing numerical differentiation algorithms. J Exp Biol 201: 981-995.

Watkins TB. 1996. Predator-mediated selection on burst swimming performance in tadpoles of the Pacific tree frog, Pseudacris regilla. Physiol Zool 69:154-167.

Webb PW. 1977. Efects of median-fin shape on fast-start performance of rainbow trout (Salmo gairdneri). J Exp Biol 68:123-135.

Webb PW. 1978. Fast-start performance and body form in seven species of teleost fish. J Exp Biol 74:211-226.

Webb PW. 1982. Fast start resistance of trout Salmo gairdneri. J Exp Biol 96:93-106.

Webb PW. 1984. Body and fin form and strike tactics of four teleost predators attacking fathead minnow. Can J Fish Sci 41:157-165.

Webb PW. 1986. Locomotion and predator-prey relationships. In: Feder ME, Lauder GV, editors. Predator-prey relationships: perspectives and approaches from the study of lower vertebrates. Chicago: University of Chicago Press. p 24-41.

Webb PW. 1988. Simple physical principles and vertebrate aquatic locomotion. Am Zool 28:709-725.

Webb PW, Gerstner CL. 2000. Swimming behavior: predictions from biomechanical principles. In: Domenici P, Blake RW, editors. Biomechanics in animal behaviour. Oxford: Bios Scientific Publishers.

Weihs D. 1972. A hydrodynamical analysis of turning manoeuvres. Proc R Soc Lond 182:59-72.

Wellborn GA, Skelly DK, Werner EE. 1996. Mechanisms creating community structure across a freshwater habitat gradient. Annu Rev Ecol Syst 27:337-363.

Werner EE. 1991. Nonlethal effects of a predator on competitive interactions between two anuran larvae. Ecology 72:1709-1720. 
Werner EE, McPeek MA. 1994. Direct and indirect effects of predators on two anuran species along an environmental gradient. Ecology 75:1368-1382.

Wilson RS, Franklin CE. 1999. Thermal acclimation of locomotor performance in tadpoles of the frog Limnodynastes peronii. J Comp Physiol B 169:445-451.

Wilson RS, Franklin CE. 2000. Effect of ontogenetic increases in body size on burst swimming performance in tadpoles of the striped marsh frog, Limnodynastes peronii. Physiol Biochem Zool 73:142-152.

Zar JH. 1996. Biostatistical analysis. Upper Saddle River, NJ: Simon \& Schuster.

Zottoli SJ, Walfish DT, Westbrooks DA, Smith DC. 2001. Small tadpoles do not initiate a startle response before being struck by the labium of dragonfly larvae. Soc Neur Abs 27: 1984. 